\title{
Necrobiosis Lipoidica: Early Diagnosis and Treatment with Tacrolimus
}

\section{A. Patsatsi A. Kyriakou D. Sotiriadis}

2nd Department of Dermatology, Aristotle University School of Medicine, Thessaloniki, Greece

\section{Key Words}

Diabetes $\cdot$ Necrobiosis lipoidica $\cdot$ Ulceration

\begin{abstract}
We present a case of necrobiosis lipoidica (NL) with atypical early lesions and good response to topical tacrolimus. NL is a disease with clinical features that are seldom misinterpreted. Often histology just confirms the clinician's diagnosis. Only in rare cases, the clinical presentation and the involved body sites may be misleading. A 67-year-old diabetic woman was admitted to our department with a well-defined, persistent plaque on her left arm and on her right shin. Histologic examination of both lesions revealed features of NL despite the dissimilar clinical presentation. The patient was treated with $0.1 \%$ topical tacrolimus ointment twice daily for 8 weeks and once daily for 8 weeks. A significant improvement and no further lesions were observed after 1 year of follow-up. A high index of suspicion regarding NL lesions with atypical clinical presentation on different body sites is advised in order to avoid misdiagnosis, wrong treatment decisions and ulceration. Additionally, it appears that topical tacrolimus treatment is an effective therapeutic option in patients with recent, non-ulcerated NL lesions.
\end{abstract}

\section{Introduction}

Necrobiosis lipoidica (NL) is a disease with clinical features that are seldom misinterpreted. Often histology just confirms the clinician's diagnosis. Only in rare cases, the clinical presentation and the involved body sites may be misleading.

\section{Case Report}

A 67-year-old woman was admitted to our department with a well-defined, persistent plaque on her right shin (fig. 1) and on her left arm (ig. 2). The old lesion, which was located on the anterior surface of the shin, was characterized by sharply defined, slightly elevated, red-bluish borders and a yelloworange, atrophic, porcelain-like center. The recent lesion presented as an erythematous plaque on the 
left arm. Both lesions were not painful, but slightly pruritic and there was no history of recent trauma or infection. The patient had a history of type 2 diabetes mellitus (DM) since 2000. Blood glucose levels had been poorly controlled ever since, with $\mathrm{HbA1C}$ reaching $7.3 \%$, but with no apparent complications of DM. The chest X-ray was completely normal. Although clinically the shin lesion was compatible with $\mathrm{NL}$, the arm lesion was not typical of any dermatosis. Therefore, both lesions were biopsied to identify their nature and rule out sarcoidosis or granuloma annulare. Histology revealed identical features despite the dissimilar clinical presentation. A granulomatous dermatitis with foci of degenerated collagen surrounded by histiocytes, some of them multinucleated (fig. 3 ), as well as thickened collagen bundles arranged horizontally in the dermis are all typical findings of NL. The patient was treated with $0.1 \%$ topical tacrolimus ointment twice daily for 8 weeks and once daily for 8 weeks. A significant improvement and no further lesions were observed after 1 year of follow-up.

\section{Discussion}

NL is a granulomatous skin disease of unknown etiology, associated mainly with DM. It more commonly occurs in women than in men with a ratio of 3:1 [1-3]. The average age of onset is 30-40 years [1-3], although it has been frequently reported in older age groups and seldom in children [2]. The lesions are distributed on the anterior and lateral surfaces of the lower legs. However, there are other sites that can rarely be affected, such as upper extremities $[1,2]$, trunk $[1,3]$, face (even periorbitally), scalp $[1,3]$ and penis $[3$, 4].

The pathogenesis of NL remains unclear. However, diabetic microangiopathy, immune-complex vasculitis, and collagen abnormalities are some potential underlying causes [1]. Nakajima et al. [5] assert that both hyperlipidemia and venous reflux, in addition to other pathogenic factors, can trigger tissue damage in the lower legs and lead to the onset of NL. In constrast, Ngo et al. [6] refute the hypothesis that NL is a manifestation of microvascular ischemic disease of the skin and conclude that the increased blood flow seen in NL lesions suggests an ongoing inflammatory process.

Despite the debates on pathogenesis, the association between DM and NL remains a fact. $75-90 \%$ of patients with NL have or will develop DM $[2,3]$. Therefore, NL is considered to be a dermatologic marker for DM [2]. In contrast, NL is present only in $0.3-3 \%$ of the diabetic population [1-3]. It is most commonly seen in patients with type 1 DM, but may also occur in type $2 \mathrm{DM}$ [7]. Whether glucose control and treatment of DM improve or have no effect on NL lesions is still a controversy $[1,2]$. NL has also been associated with other diseases such as sarcoidosis, rheumatoid arthritis, autoimmune thyroid disease and inflammatory bowel disease [3].

NL presents spontaneous remission in less than $20 \%$ of cases [1]. Ulceration is the most frequent and hard to treat complication of NL in $25-33 \%$ of patients [1-3]. Additionally, squamous cell carcinoma developing in areas of NL has also been reported [1-3].

Although there are plenty therapeutic options for NL, its treatment is still challenging and sometimes ineffective [1,2]. First-line treatment includes corticosteroids, either topically or intralesionally, and sometimes systemically $[1-3,8]$. According to some reports, smoking cessation and blood glucose control is recommended [1,2]. Other therapeutic options are antiplatelet agents [3], cyclosporine [1-3, 8], thalidomide [3,8], clofazimine [2], anti-TNF agents [3,8], fumaric acid esters [2, 8], PUVA [2, 3, 8], photodynamic therapy $[8,9]$, hydroxychloroquine [10] and tacrolimus $[3,11-13]$. 
We report a case of non-ulcerated, recent lesions of NL well managed with topical tacrolimus $0.1 \%$ ointment twice daily for 8 weeks and once daily for 8 weeks. Despite the limited experience with topical tacrolimus treatment in NL, the few existing references seem quite encouraging (table 1). Tacrolimus induces anti-inflammatory and immunomodulatory effects with suppression of the granulomatous infiltrate in granuloma annulare and NL, including the reduction of chemotactic activity of fibroblasts and the inhibition of collagen synthesis [11-13]. Subsequently, tacrolimus is thought to be effective at the early inflammatory stages of NL.

Making a diagnosis of NL of the lower legs is not difficult; however, a high index of suspicion regarding NL lesions with atypical clinical presentation on different body sites is advised in order to avoid misdiagnosis, wrong treatment decisions and ulceration. Additionally, it appears that topical tacrolimus treatment is an effective therapeutic option in patients with recent, non-ulcerated NL lesions.

\section{Disclosure Statement}

The authors have no conflict of interest to declare.

Table 1. Use of $0.1 \%$ topical tacrolimus ointment in $\mathrm{NL}$

\begin{tabular}{llcl}
\hline First author & $\begin{array}{l}\text { Number of } \\
\text { patients }\end{array}$ & Treatment & Outcome \\
\hline Barth [12] & 1 & 12 weeks & Improvement \\
Clayton [11] & 1 & 1 month & Improvement \\
Harth [13] & 2 & 8 weeks & Improvement \\
\hline
\end{tabular}

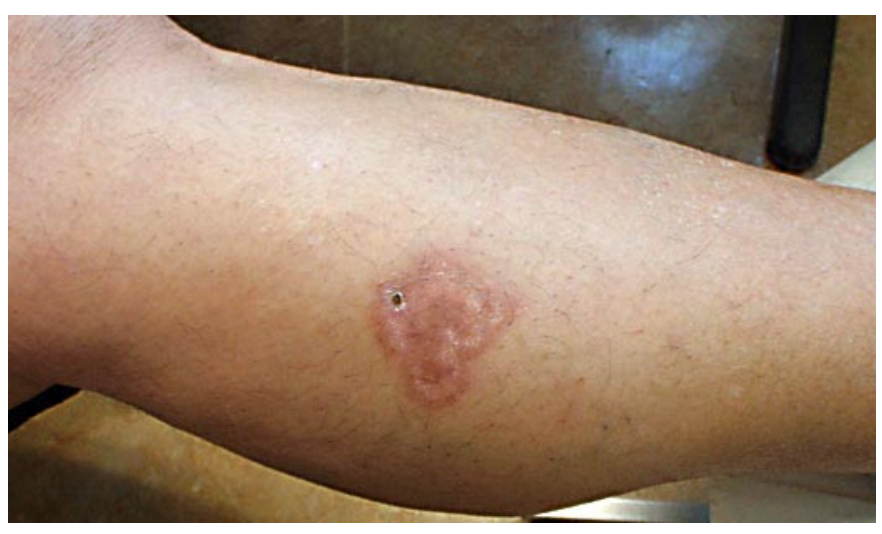

Fig. 1. Lesion on the right shin. 


\begin{tabular}{l|l|l|l}
$\begin{array}{c}\text { Case Reports in } \\
\text { Dermatology }\end{array}$ & $\begin{array}{l}\text { Case Rep Dermatol 2011;3:89-93 } \\
\text { DOI: 10.1159/000327936 }\end{array}$ & $\begin{array}{l}\text { Published online: } \\
\text { April 18, 2011 }\end{array}$ & $\begin{array}{l}\text { O 2011 S. Karger AG, Basel } \\
\text { ISSN 1662-6567 } \\
\text { www.karger.com/cde }\end{array}$ \\
\hline
\end{tabular}

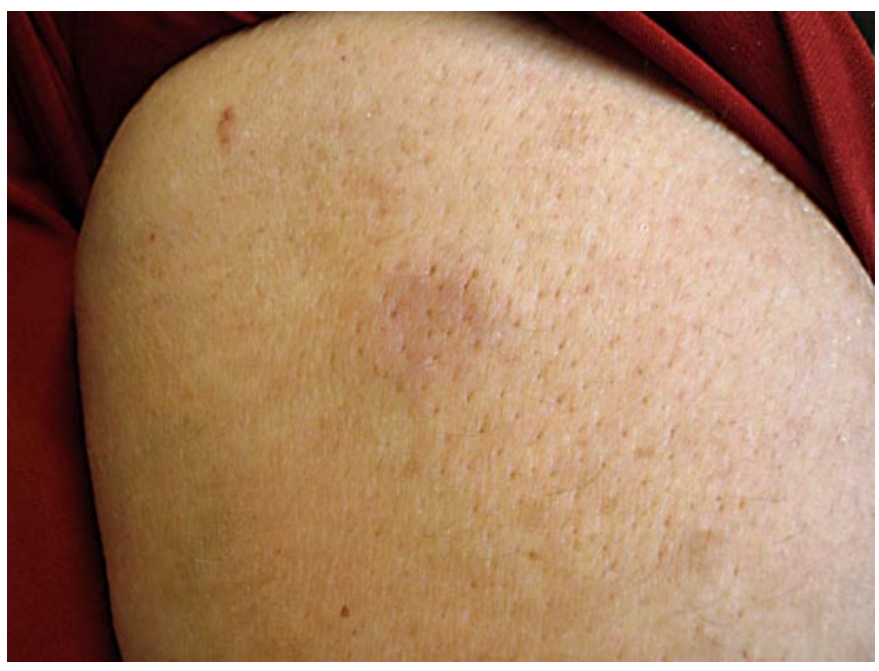

Fig. 2. Lesion on the left arm.

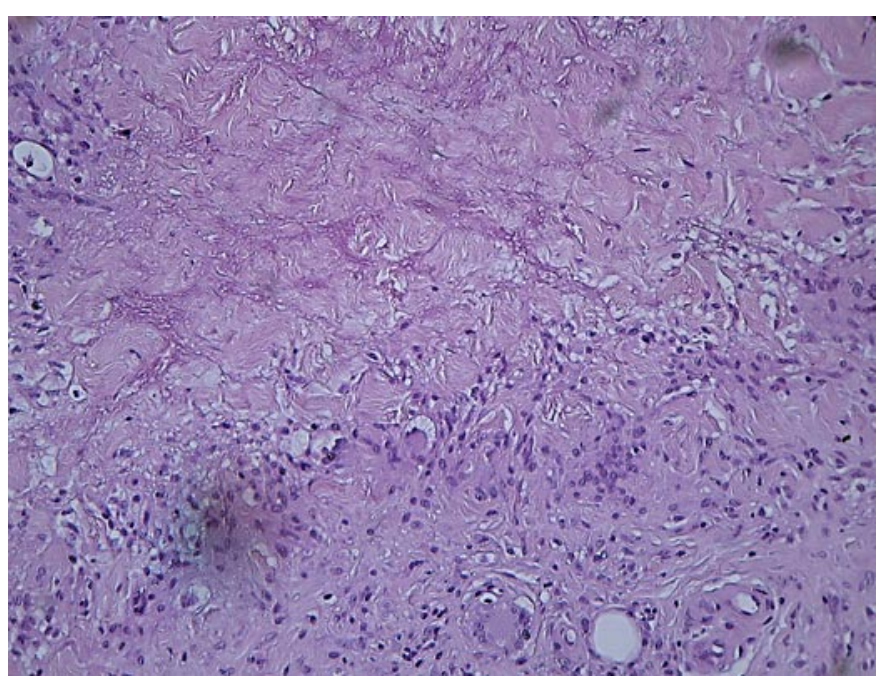

Fig. 3. Foci of degenerated collagen surrounded by histiocytes; some of them were multinucleated; HE $\times 40$. 


\section{References}

1 Gottrup F, Karlsmark T: Leg ulcers: uncommon presentations. Clin Dermatol 2005;23:601-611.

- Hammami H, Youssef S, Jaber K, Dhaoui MR, Doss N: Perforating necrobiosis lipoidica in a girl with type 1 diabetes mellitus: a new case reported. Dermatol Online J 2008;14:11.

$\checkmark 3$ Peyri J, Moreno A, Marcoval J: Necrobiosis lipoidica. Semin Cutan Med Surg 2007;26:87-89.

-4 Alonso ML, Riós JC, González-Beato MJ, Herranz P: Necrobiosis lipoidica of the glans penis. Acta Derm Venereol 2011;91:105-106.

5 Nakajima T, Tanemura A, Inui S, Katayama I: Venous insufficiency in patients with necrobiosis lipoidica. J Dermatol 2009;36:166-169.

6 Ngo B, Wigington G, Hayes K, Huerter C, Hillman B, Adler M, Rendell M: Skin blood flow in necrobiosis lipoidica diabeticorum. Int J Dermatol 2008;47:354-358.

7 Sehgal V, Bhattacharya S, Verma P: Juvenile, insulin-dependent diabetes mellitus, type 1-related dermatoses. J Eur Acad Dermatol Venereol 201025 Nov 2010.10.1111/j.1468-3083.2010.03912.x. [Epub ahead of print].

$\checkmark 8$ Eberle FC, Ghoreschi K, Hertl M: Fumaric acid esters in severe ulcerative necrobiosis lipoidica: a case report and evaluation of current therapies. Acta Derm Venereol 2010;90:104-106.

-9 Berking C, Hegyi J, Arenberger P, Ruzicka T, Jemec GB: Photodynamic therapy of necrobiosis lipoidica - a multicenter study of 18 patients. Dermatology 2009;218:136-139.

10 Kavala M, Sudogan S, Zindanci I, Kocaturk E, Can B, Turkoglu Z, Altintas S: Significant improvement in ulcerative necrobiosis lipoidica with hydroxychloroquine. Int J Dermatol 2010;49:467-469.

11 Clayton TH, Harrison PV: Successful treatment of chronic ulcerated necrobiosis lipoidica with $0.1 \%$ topical tacrolimus ointment. Br J Dermatol 2005;152:581-582.

12 Barth D, Harth W, Treudler R, Simon JC: Topical tacrolimus in necrobiosis lipoidica. Hautarzt 2010 Oct 15 [Epub ahead of print].

13 Harth W, Linse R: Topical tacrolimus in granuloma annulare and necrobiosis lipoidica. Br J Dermatol 2004;150:792-794. 